\title{
The Verification of Rail Thermal Stress Measurement System
}

\author{
Duan Xiangyu ${ }^{1,2}$, Zhu Liqiang ${ }^{1,2^{*}}$, Yu Zujun ${ }^{1,2}$, Xu Xining ${ }^{1,2}$ \\ ${ }^{1}$ School of Mechanical, Electronic Control Engineering, Beijing Jiaotong University, \\ No.3 Shangyuancun, Haidian District, Beijing 100044, China \\ ${ }^{2}$ Key Laboratory of Vehicle Advanced Manufacturing, Measuring and Control Technology (Beijing Jiaotong University), \\ Ministry of Education, No.3 Shangyuancun, Haidian District Beijing 100044, China \\ ${ }^{*}$ Corresponding author, e-mail: Iqzhu@bjtu.edu.cn
}

Received: 08 February 2018, Accepted: 11 September 2018, Published online: 16 April 2019

\begin{abstract}
Continuous Welded Rail (CWR) is widely used in modern railways. With the absence of the expansion joints, CWR cannot expansion freely when the temperature changes, which could cause buckling in hot weather or breakage in cold weather. Therefore, rail thermal stress measuring system plays an important role in the safe operation of railways. This paper designed a thermal stress measurement system based on the acoustoelastic effect of the ultrasonic guided wave. A large-scale rail testbed was built to simulate the thermal stress in the rail track, and to establish the relationship of time-delay of guided wave and thermal stress. After laboratory testing, the system was installed in several railway lines in China for field tests. The results showed that the system was stable and accurate in stress measurement. The performance and potentials of the system were discussed.
\end{abstract}

\section{Keywords}

system verification, continuous welded rail, thermal stress, guided wave

\section{Introduction}

Most modern railways use Continuous Welded Rail (CWR). The absence of expansion joints leads to the reduction of the noise and comfortability of the railway. However, the rail buckling and breakage could happen in hot weather and cold weather respectively due to the thermal stress in CWR. It is important to develop an on-line monitoring system to monitor the state of CWR to ensure the safety of the railway transportation.

Thermal stress is related to the neutral temperature or lock temperature, defined as the temperature corresponding to a stress-free condition in the rail. Thermal stress can be measured by

$\sigma_{t}=E \cdot \varepsilon=E \cdot \frac{\alpha \cdot \Delta T \cdot l}{l}=E \cdot \alpha \cdot \Delta T$

where

$\sigma_{t}$ is thermal stress in the rail,

$E$ is Young's modulus of steel,

$\varepsilon$ is strain of the rail,

$l$ is length of the rail,

$\alpha$ is coefficient of thermal expansion of steel,

and $\Delta T$ is the difference between rail temperature and neutral temperature
According to the Eq. (1), thermal stress is in liner relationship with the change of the temperature. When the temperature change reaches the 50 degrees, stress in the rail is about $125 \mathrm{MPa}$. The huge thermal stress may cause rail buckling or rail breakage.

Various measurement techniques have been proposed for the stress measurement (Kandil et al., 2001). Destructive methods would affect the integrity of the rail track. Rail-uplift (Kish et al., 1993) method need to release the fasteners of rail for $30 \mathrm{~m}$ length and the vertical force needed to lift the center by a fixed amount is measured. Vibration techniques have also been proposed based on the change of resonant frequencies influenced by the axial load (Luo, 1999). Damijanovic and Weaver (2005) used scanning laser vibrometer to measure the wavenumber of the spatial distribution of vibration amplitude in response to imposed dynamic loads at a frequency of $200 \mathrm{~Hz}$. This method requires that the rail is released from the sleepers for a considerable length. The strain gauge provides an easily applicable approach to measure the relative stress. However, it can only measure the surface strain and must know the initial value to get an absolute strain. X-ray diffraction can measure absolute strain, but X-rays penetrate 
only the surface. Magnetic hysteresis is similarly dependent only on surface properties. The traditional ultrasonic bulk wave can measure the stress level of the region being insonified (Rose, 2014).

Guided waves have been widely used in structural health monitoring and have great potentials in testing in rail (Rose, 2014). In 2012, Burger described the implementation of a system using guided waves to continuously monitor the rail for breaks (Burger, 2012). Nucera utilized nonlinear guided waves to measure the rail neutral temperature and realized an accuracy within $\pm 5^{\circ} \mathrm{F}$ (Nucera et al., 2013). In 2014, Xu proposed a method to select and excite a particular ultrasonic guided wave mode for the stress detection (Xu et al., 2014). However, up to now, there is no online monitoring system to measure the thermal stress in rail reliably.

In this paper, a guided wave ultrasound system for measuring the thermal stress in rail has been developed. The ultrasonic guided waves propagate throughout the rail section, which can measure the inner average stress of propagation paths in the rail. Permanently attached transducers are used to accomplish the on-line measurement of stress with no interference to the normal transportation of railways. A large-scale rail testbed has been designed to simulate the thermal stress in the real track and establish the relationship between the time delays and the thermal stress. Field test verifications have been applied in several high-speed railway lines in China. The results are presented and discussed.

\section{System Design}

The concept of the thermal stress online monitoring system is illustrated in Fig. 1. The system consists of three main parts:

1. guided wave processing module,

2. solar power source and

3. terminal computer with WCDMA wireless module

The dispersion curves provide basic information on guided wave such as phase and group velocities as well as wavelength, Fig. 2 shows the dispersion curves of guided waves in CHN60 rail.

The dispersion curves are obtained by semi-analytical finite element technique. The system utilizes a mode and its propagation is mainly confined to the web of the rail. Mode shape of the selected mode is illustrated in Fig. 3.

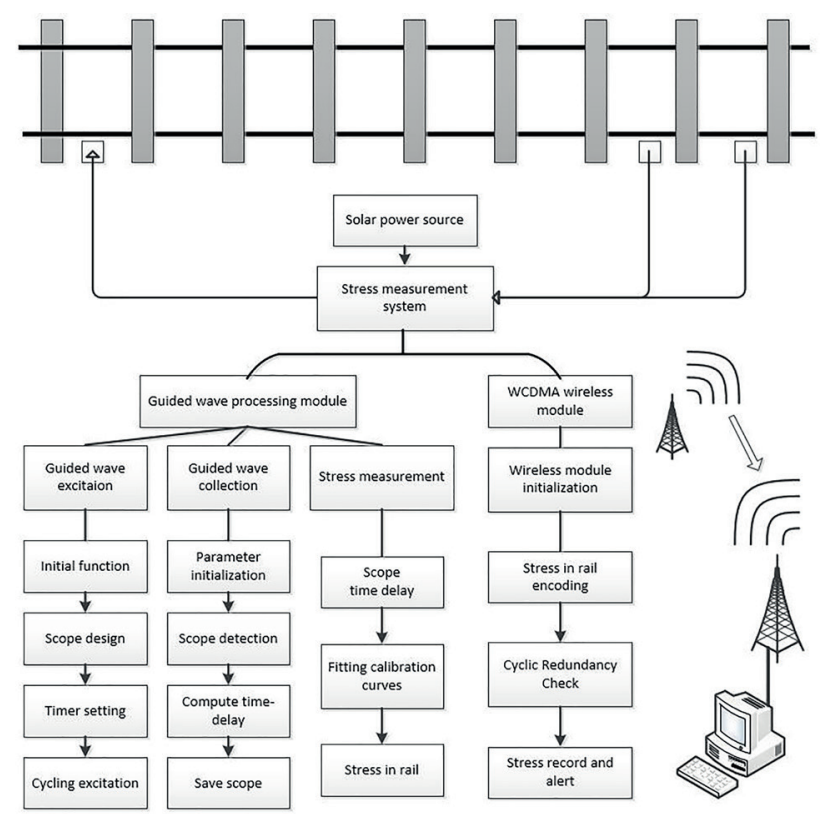

Fig. 1 Framework of online monitoring of thermal stress system

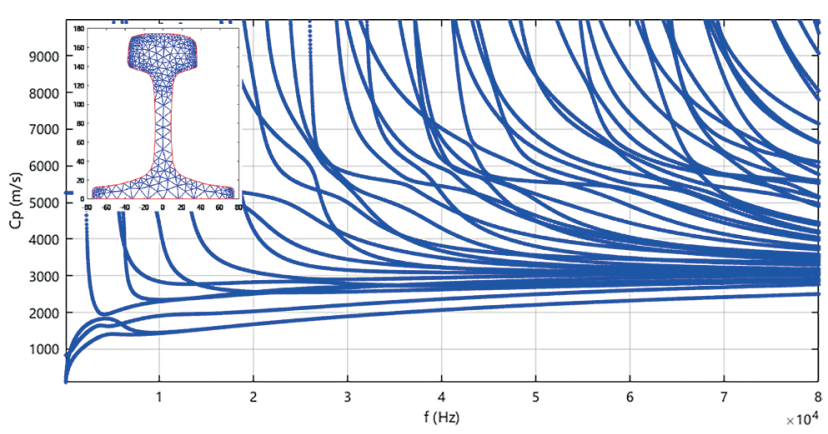

Fig. 2 Dispersion curve of phase velocity vs frequency

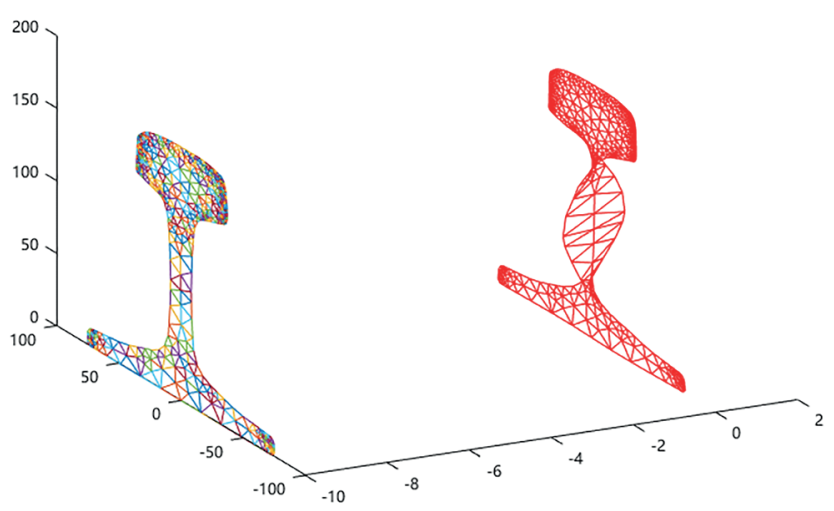

Fig. 3 Mode shape of selected mode

\subsection{Guided wave processing module}

The guided wave processing module has three main tasks, guided wave excitation, guided wave collection, and stress measurement. Guided waves were excited with a $200 \mathrm{~V}$, five-cycle Hanning windowed sine wave at $35 \mathrm{kHz}$ every five minutes. 
Two transducers with a certain spacing received the guided wave signals and their outputs were sampled at the same time. The sampling frequency of the data acquisition is $10 \mathrm{MHz}$. The Fast Fourier Transform (FFT) is used to distinguish the guided wave signals from low-frequency noise that could be generated by electromagnetic interference sources, e.g. track circuits. Received waveforms will be saved in the SD card if the amplitude of $35 \mathrm{kHz}$ is twice of the other frequency components. Time delays of two channels are computed from enveloped received waveforms.

\subsection{Relationship of time-delay and stress}

Phase and group velocities are two basic properties of guided waves. During the propagation of guided waves, stress in rail will affect the phase and group velocities, which is known as acoustoelastic theory (Hughes and Kelly, 1953; Murnaghan, 1937). The theory has been developed in the case of plane waves for isotropic materials with infinite dimensions.

For a homogeneous and isotropic infinite solid subjected to a uniaxial stress, the bulk velocities of longitudinal and transverse plane waves, propagating in the same direction as the applied stress, can be written in the first-order approximation, respectively, as

$$
\begin{aligned}
& V_{L}^{\sigma}=\sqrt{\frac{\lambda+2 \mu}{\rho}\{1}\left\{\frac{\sigma}{2(\lambda+2 \mu)(3 \lambda+2 \mu)}\right. \\
& \left.\times\left[\frac{\lambda+\mu}{\mu}(4 \lambda+10 \mu+4 m)+\lambda+2 l\right]\right\} \\
& V_{T}^{\sigma}=\sqrt{\frac{\mu}{\rho}}\left[1+\frac{\sigma}{2 \mu(3 \lambda+2 \mu)} \times\left(4 \lambda+10 \mu+m+\frac{\lambda n}{4 \mu}\right)\right]
\end{aligned}
$$

where $\rho$ is the mass density of the material, $\sigma$ is the tensile stress, $\lambda$ and $\mu$ are Lame's elastic constants, and $m, n, l$ are Murnaghan's third order elastic constants.

These equations can be simplified as follows:

$$
\begin{aligned}
& V_{L}^{\sigma}=V_{L}^{0}\left(1+K_{L} \sigma\right) \\
& V_{T}^{\sigma}=V_{T}^{0}\left(1+K_{T} \sigma\right)
\end{aligned}
$$

where $V_{L}^{0}$ and $V_{T}^{0}$ are the initial longitudinal and transverse wave velocities in the stress-free medium respectively, $K_{L}$ and $K_{T}$ are longitudinal and transverse acoustoelastic coefficients representing the response of the stressed material to the wave propagation (Chaki and Bourse, 2009).
For the case of rail thermal stress, the guided wave mode that mainly propagates in the rail web can be regarded as a longitudinal wave. The Eq. (4) can be rewritten as

$$
\frac{\Delta V}{V_{0}}=\frac{V_{\sigma}-V_{0}}{V_{0}}=K \sigma
$$

Since the time-of-flight in a certain length of $l_{0}$ with zero axial load is $t_{0}=l_{0} / V_{0}$, the following equation can be obtained

$\frac{\frac{l_{s}}{t_{\sigma}}-\frac{l_{0}}{t_{0}}}{\frac{l_{0}}{t_{0}}}=K \sigma$

where $l_{s}$ is the rail length under stress and $t_{\sigma}$ is the time-offlight under stress.

For in-situ rail constrained by fasteners cannot expansion freely. Eq. (7) can be rewritten as

$$
\frac{t_{0}-t_{\sigma}}{t_{\sigma}}=\frac{\Delta t}{t_{\sigma}}=K \sigma
$$

The coefficient $K$ can be obtained by a calibration test in the laboratory. If we applied known tensile or pressure stress to the rail, transducers can detect the changes of timeof-flight and the coefficient of the rail can be computed.

There are two approaches to simulate the stress in rail. One is to change the temperature of the rail and calculate the stress inside rail according to the lock rail temperature. The other one is to apply pressure or tensile load to rail; the stress inside the rail can be measured by the sensors. Because it is difficult to accurately control the temperature of rail, the second approach is easier to get better accuracy in the simulation of stress.

A large-scale rail-stretch experiment platform has been constructed to induce the stress in rail (Fig. 4). This platform has two 6-meter long rails with CTRS-II rail plate. One end of the rail is fixed, and the other end is connected with a hydraulic system, which can apply pressure or tensile force to the rail. Table 1 shows the parameters of the hydraulic system.
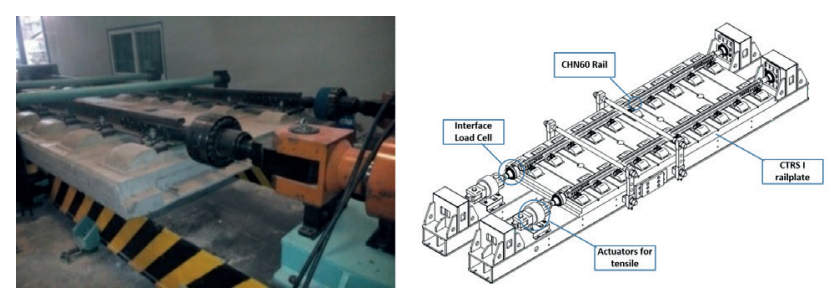

Fig. 4 Large-scale rail stretch experimental platform 


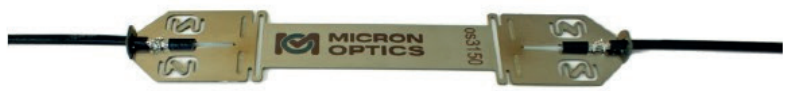

Fig. 5 Fiber Bragg Grating strain gauge

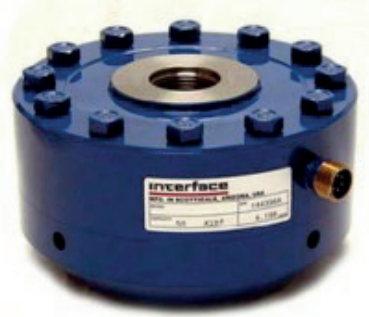

Fig. 6 Load cell from the Interface Force

Table 1 Parameters of the hydraulic system

\begin{tabular}{cccc}
\hline $\begin{array}{c}\text { Rail } \\
\text { sectional } \\
\text { area }\end{array}$ & $\begin{array}{c}\text { hydraulic cylinder } \\
\text { cross-sectional } \\
\text { area of push }\end{array}$ & $\begin{array}{c}\text { Load } \\
\text { force } \\
\mathbf{( k N )}\end{array}$ & $\begin{array}{c}\text { Stress in the rail } \\
\text { (MPa) }\end{array}$ \\
\hline $0.0077 \mathrm{~m}^{2}$ & $0.0491 \mathrm{~m}^{2}$ & 49.0874 & 6.3363 \\
\hline $\begin{array}{c}\text { Rail } \\
\text { sectional } \\
\text { area }\end{array}$ & $\begin{array}{c}\text { hydraulic cylinder } \\
\text { cross-sectional } \\
\text { area of pull }\end{array}$ & $\begin{array}{c}\text { Load } \\
\text { force } \\
(\mathbf{k N})\end{array}$ & $\begin{array}{c}\text { Stress in the rail } \\
(\mathbf{M P a})\end{array}$ \\
\hline $0.0077 \mathrm{~m}^{2}$ & $0.0378 \mathrm{~m}^{2}$ & 37.7780 & 4.8760 \\
\hline
\end{tabular}

The stress in rail can be accurately calculated with the knowledge of the load force and contact area when the rail temperature does not change. The platform employed two Interface Model 1200 Standard High Capacity Load Cells to measure the load that applied to the rail. The load cells can measure accurate loads with a static error band less than $0.7 \%$. The FBG (Fiber Bragg Grating) strain gauge from Micron Optics was also installed at rail web to measure the rail stress for comparison with the Load Cell.

Thirteen different stress values were chosen as sample points. The guided wave processing module acquired the time delays of two receiving transducers. Table 2 shows the results of time delay and the stress value, where a negative value means tensile stress and a positive value means pressure stress. Time delays in the table are the average of ten measurements.

The calibration curve that represents function relationship between time delays and stress was obtained by data normalization and least square fitting. Tensile stress and pressure stress were separated to get better accuracy. Fig. 7 and Fig. 8 show the calibration curves of stress vs time delays.

\subsection{WCDMA wireless module}

The measured rail stress information was converted into a specific format for transmission. The information was first
Table 2 Time delay and stress value

\begin{tabular}{lcc}
\hline Index & Stress value $(\mathrm{MPa})$ & Time delay $(\mathrm{ns})$ \\
\hline 1 & -123.85 & 324290.0 \\
2 & -104.27 & 324327.0 \\
3 & -88.65 & 324353.8 \\
4 & -70.69 & 324375.5 \\
5 & -49.22 & 324430.4 \\
6 & -36.25 & 324484.0 \\
7 & 0.00 & 324552.7 \\
8 & 29.77 & 324695.2 \\
9 & 47.48 & 324758.7 \\
10 & 61.70 & 324774.1 \\
11 & 72.04 & 324800.3 \\
12 & 82.41 & 324831.6 \\
13 & 91.61 & 324851.4 \\
\hline
\end{tabular}

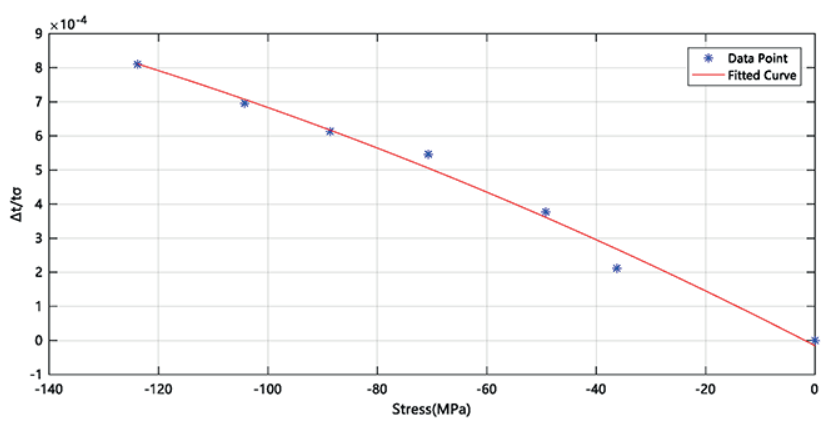

Fig. 7 Calibration curve of pressure stress vs time delays

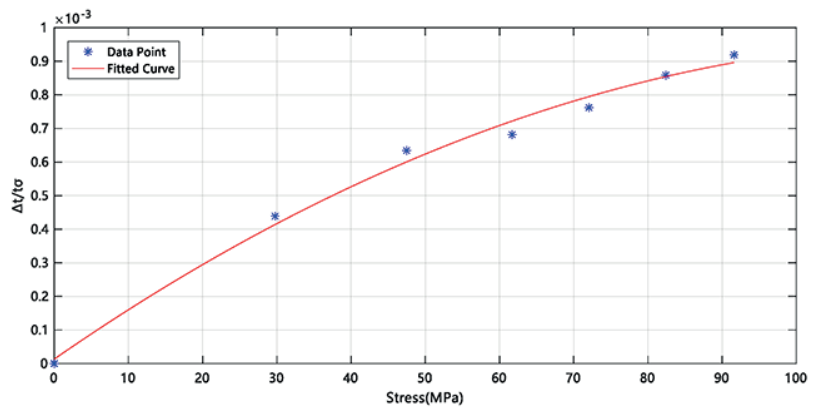

Fig. 8 Calibration curve of tensile stress vs time delays

transmitted to a cloud server and then downloaded to the remote terminal. The wireless module was initialized with a baud rate of $19200 \mathrm{bps}$ and used WCDMA technique to accomplish the communication.

The error control of data transmission was ensured by a cyclic redundancy check. The remote terminal can inform engineers of stress information via a short message. When the stress in rail exceeds the limit value, timely alarm can ensure the safety of railway operation. 


\subsection{Laboratory test}

Laboratory tests were carried out in order to verify the reliability of the stress measurement system and the accuracy of the calibration curves.

The stress measurement system was installed as mentioned in Fig. 1. Transducers were dry-coupled to the rail of large-scale rail stretch experimental platform. The stress measurement system ran continuously for 48 hours in a laboratory environment without failure.

Six new stress values were selected to test the accuracy of the calibration curves. With each stress value, the guided wave processing module recorded time delays between two transducers and calculate the stress in rail using the calibration curves obtained in Section 2.2. Table 3 shows the results of accuracy tests and the absolute error is smaller than $5 \mathrm{MPa}$.

\section{Results}

The stress measurement system was installed in DatongXi'an high-speed railway in Dec 2014 and Tianjin-Baoding high-speed railway in July 2015 (Duan et al., 2016). Three monitoring stations were installed along $5 \mathrm{~km}$ rail. Fig. 9 shows the installation of the system in the Datong-Xi'an high-speed railway.

The results showed that the stability of the system is quite well and only a few equipment failures occurred during the six months of monitoring of Datong-Xi'an

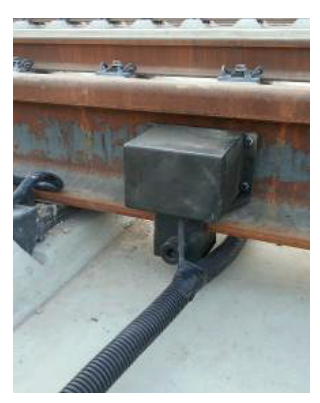

(a)

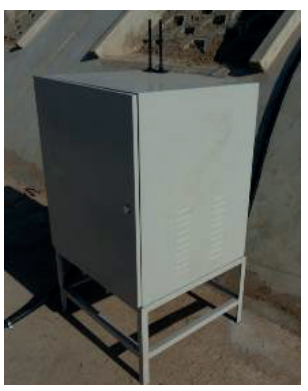

(c)

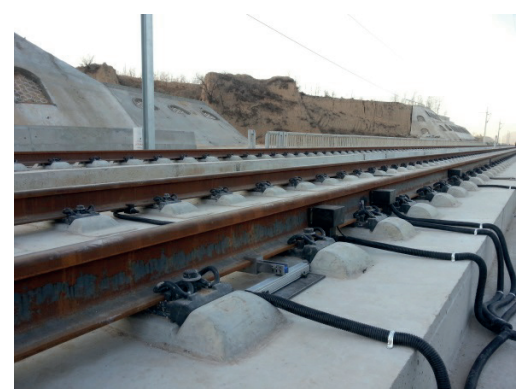

(b)

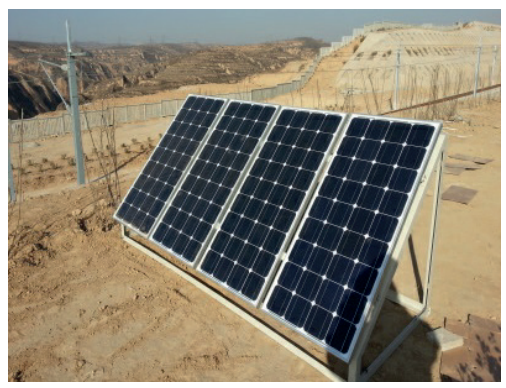

(d)
Fig. 9 (a) Piezoelectric transducer and holder, (b) layout of transmit and receive transducers, (c) solar panel, (d) receive station
Table 3 Laboratory test result

\begin{tabular}{lcccc}
\hline Index & $\begin{array}{c}\text { Stress value } \\
(\mathrm{MPa})\end{array}$ & $\begin{array}{c}\text { Time delay } \\
(\mathrm{ns})\end{array}$ & $\begin{array}{c}\text { Measured } \\
\text { Stress Value } \\
(\mathrm{MPa})\end{array}$ & $\begin{array}{c}\text { Absolute } \\
\text { error }\end{array}$ \\
\hline 1 & -110.82 & 324315.0 & -108.31 & 2.51 \\
2 & -75.61 & 324360.0 & -78.45 & 2.84 \\
3 & -25.82 & 324520.8 & -22.96 & 2.86 \\
4 & 30.44 & 324698.5 & 33.45 & 3.01 \\
5 & 65.28 & 324791.4 & 67.61 & 2.33 \\
6 & 85.69 & 324851.0 & 88.45 & 2.76 \\
\hline
\end{tabular}

railway. The system occurred a few communication failures for receive stations located in the valley, and while receive stations located in the plane get better performance.

Fig. 10 and Fig. 11 illustrate the performance of the system at two locations in a month.

Fig. 12 shows the unfiltered waveform received on the remote terminal. A Butterworth filter was designed to filter the received data by using MATLAB software. Envelop technique is used to calculate the time delays between two transducers. Fig. 13 shows the filtered and enveloped waveform. Fig. 14 shows the filtered and enveloped waveforms of two receive transducers. The first wave packet is generated by the air coupling of the excitation signal.

According to the calibration curves in Section 2.2, each time delay corresponds to one rail thermal stress. Fig. 15 shows the rail temperature and rail stress curves.

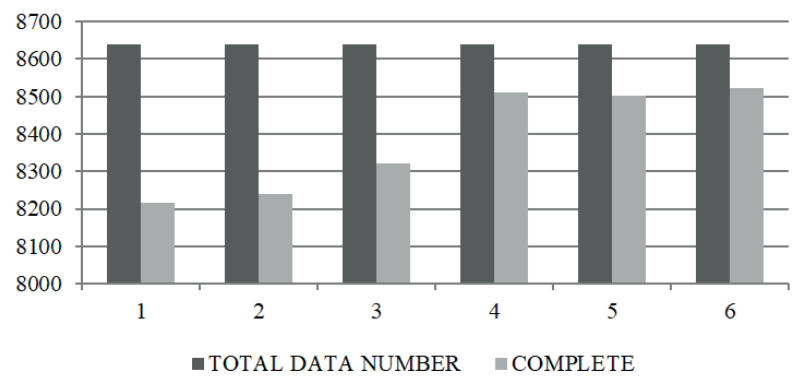

Fig. 10 Performance of the system in field tests

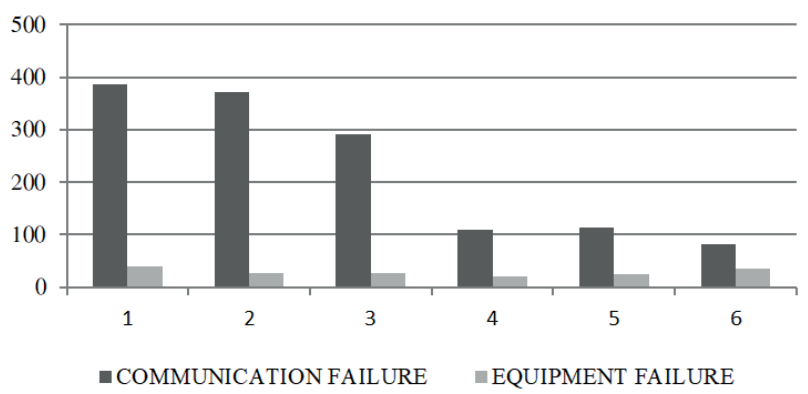

Fig. 11 Failure types of the system in field tests 


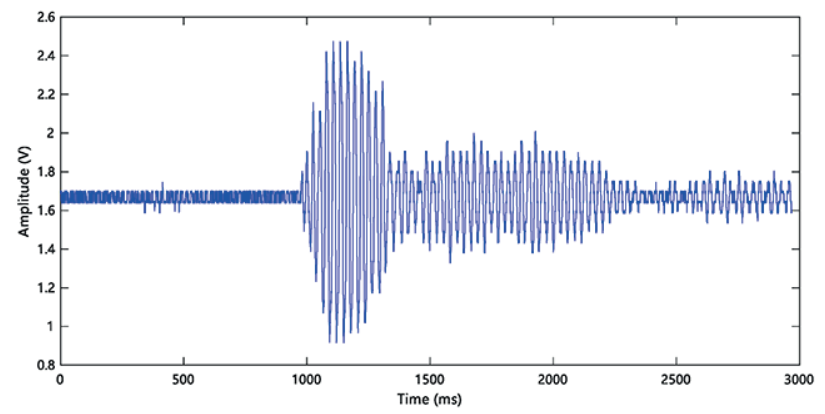

Fig. 12 Unfiltered waveform

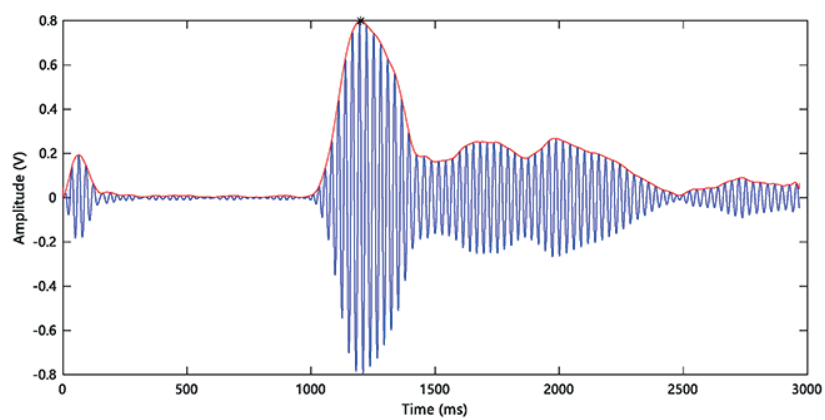

Fig. 13 Filtered and enveloped waveform

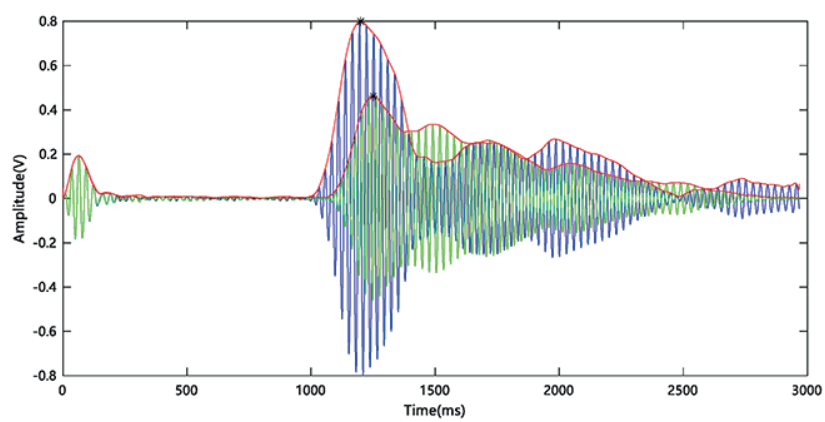

Fig. 14 Waveforms from two transducers

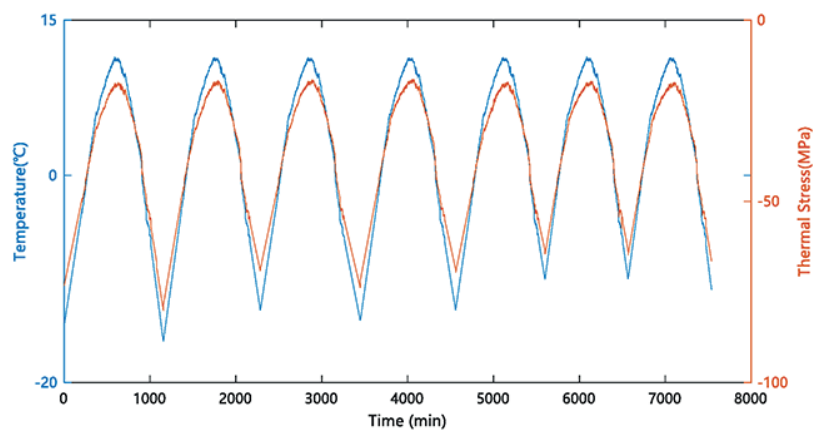

Fig. 15 Rail Temperature and thermal stress curves in winter

Rail temperatures were obtained by the digital temperature sensors. Thermal stress shows good consistency with rail temperature. Theoretical thermal stress in rail can be calculated by Eq. (1) with rail temperature and lock temperature. The accuracy of thermal stress measurement
Table 4 Accuracy of measurement

\begin{tabular}{|c|c|c|c|c|}
\hline Index & $\begin{array}{l}\text { Measured } \\
\text { value } \\
(\mathrm{MPa})\end{array}$ & $\begin{array}{c}\text { Temperature } \\
\left({ }^{\circ} \mathrm{C}\right)\end{array}$ & $\begin{array}{c}\text { Theoretical } \\
\text { value } \\
(\mathrm{MPa})\end{array}$ & $\begin{array}{c}\text { Measuring } \\
\text { error } \\
(\mathrm{MPa})\end{array}$ \\
\hline 1 & -47.32 & -2.54 & -54.76 & 7.44 \\
\hline 2 & -25.00 & 8.11 & -28.90 & 3.90 \\
\hline 3 & -26.32 & 6.32 & -33.24 & 6.92 \\
\hline 4 & -37.21 & 1.33 & -45.36 & 8.15 \\
\hline 5 & -25.35 & 8.07 & -29.00 & 3.65 \\
\hline 6 & -64.25 & -9.91 & -72.69 & 8.44 \\
\hline 7 & -60.10 & -7.98 & -68.00 & 7.90 \\
\hline 8 & -28.47 & 4.90 & -36.68 & 8.21 \\
\hline 9 & -32.14 & 4.87 & -36.76 & 4.62 \\
\hline 10 & -43.26 & -1.07 & -51.19 & 7.93 \\
\hline 11 & 20.19 & 31.17 & 14.99 & 5.20 \\
\hline 12 & 63.09 & 49.60 & 59.78 & 3.31 \\
\hline 13 & 70.82 & 52.12 & 65.90 & 4.92 \\
\hline 14 & 14.44 & 29.81 & 11.69 & 2.75 \\
\hline 15 & 20.69 & 31.41 & 15.58 & 5.11 \\
\hline 16 & 41.15 & 40.13 & 36.77 & 4.38 \\
\hline 17 & 30.53 & 35.89 & 26.46 & 4.07 \\
\hline 18 & 14.45 & 29.21 & 10.23 & 4.22 \\
\hline 19 & 80.62 & 57.00 & 77.76 & 2.86 \\
\hline 20 & 16.82 & 30.48 & 13.32 & 3.50 \\
\hline
\end{tabular}

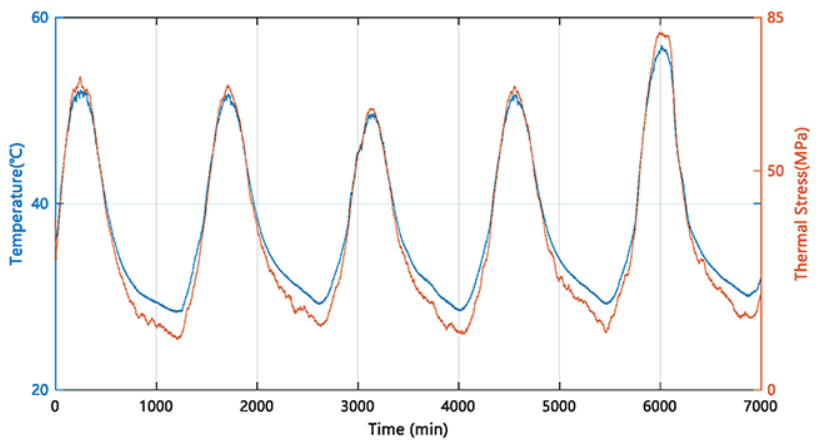

Fig. 16 Rail Temperature and thermal stress curves in summer

can be obtained by comparing theoretical values with the measured values. Table 4 shows the accuracy of the measurement. The theoretical value is calculated with the lock temperature of $20^{\circ} \mathrm{C}$ and $25^{\circ} \mathrm{C}$. Measurement errors of all ten sampling points are less than $10 \mathrm{MPa}$.

Six months of testing shows that the thermal stress measurement is stable and accurate. The measurement system achieved a measurement error of less than $10 \mathrm{MPa}$. It has to be noted that the temperature can also affect the velocity of the guided wave, the calibration curves of time delays and stress should be extended to a database consist of curves with a series of temperatures to get better results. 


\section{Acknowledgement}

The research is supported by The National Key Research and Development Program of China (2016YFB1200401).

\section{References}

Burger, F. A. (2012) "A practical continuous operating rail break detection system using guided waves", In: 18th World Conference on Non-destructive Testing, Durban, South Africa, 2012, p. 8. [online] Available at: https://www.ndt.net/article/wcndt2012/papers/627_ wcndtfina100627.pdf [Accessed: 07 February 2018]

Chaki, S., Bourse, G. (2009) "Guided ultrasonic waves for non-destructive monitoring of the stress levels in prestressed steel strands", Ultrasonics, 49(2), pp. 162-171. https://doi.org/10.1016/j.ultras.2008.07.009

Damljanović, V., Weaver, R. L. (2005) "Laser vibrometry technique for measurement of contained stress in railroad rail", Journal of sound and vibration, 282(1), pp. 341-366.

https://doi.org/10.1016/j.jsv.2004.02.055

Duan, X., Yu, Z., Zhu, L., Xu, X. (2016) "Monitoring system of thermal stress for continuous welded rails", WIT Transactions on The Built Environment, 162, pp. 239-249. https://doi.org/10.2495/CR160221

Hughes, D. S., Kelly, J. (1953) "Second-order elastic deformation of solids", Physical Review, 92(5), pp. 1145-1149. https://doi.org/10.1103/PhysRev.92.1145

Kandil, F., Lord, J., Fry, A., Grant, P. (2001) "A review of residual stress measurement methods. A Guide to Technique Selection", National Physical Laboratory, Teddington, UK, Report MATC(A)04.

Kish, A., Kalay, S., Hazell, A., Schoengart, J., Samavedam, G. (1993) "Rail longitudinal force measurement evaluation studies using the track loading vehicle", American Railway Engineering Association Bulletin, 742, pp. 315-342.
Luo, Y. (1999) "A model for predicting the effect of temperature force of continuous welded rail track", Proceedings of the Institution of Mechanical Engineers, Part F: Journal of Rail and Rapid Transit, 213(2), pp. 117-124. https://doi.org/10.1243/0954409991531074

Murnaghan, F. D. (1937) "Finite deformations of an elastic solid", American Journal of Mathematics, 59(2), pp. 235-260. https://doi.org/10.2307/2371405

Nucera, C., Phillips, R., di Scalea, F. L., Fateh, M., Carr, G. (2013) "System for In Situ Measurement of Neutral Temperature in Continuous-Welded Rail: Results from Laboratory and Field Tests", Transportation Research Record, 2374(1), pp. 154-161. https://doi.org/10.3141/2374-18

Rose, J. L. (2014) "Ultrasonic guided waves in solid media", Cambridge University Press. New York, USA. https://doi.org/10.1017/CBO9781107273610

Xu, X., Ye, Y., Jiang, C., Yu, Z., Ke, Z. (2014) "Research on method for mode selection of guided ultrasonic waves in stress measurement of rails", Chinese Journal of Scientific Instrument, 35(11), pp. $2473-2483$.

https://doi.org/10.19650/j.cnki.cjsi.2014.11.009 